\title{
Could Fire Severity Promotes the Biosynthesis of Bioactive Compounds as a Strategy to Improve Plant Survival? ${ }^{\dagger}$
}

\author{
Ana Carolina Santacruz-García ${ }^{1, *}$, Mónica Azucena Nazareno ${ }^{1}$ and Sandra Bravo 2,* \\ 1 Consejo Nacional de Investigaciones Científicas y Técnicas CONICET and Instituto de Ciencias Químicas, \\ Facultad de Agronomía y Agroindustrias, Universidad Nacional de Santiago Del Estero, Santiago del \\ Estero. C.P. 4200, Argentina; manazar2004@yahoo.com \\ 2 Instituto de Silvicultura y Manejo de Bosques-INSIMA, Universidad Nacional de Santiago del Estero, \\ Santiago del Estero. C.P. 4200, Argentina \\ * Correspondence: anacaro.santacruz@gmail.com (A.C.S.-G.); sandrabrav@gmail.com (S.B.); \\ Tel.: +54-9-385-474-4264 (A.C.S.-G.) \\ + Presented at the 1st International Electronic Conference on Forests - Forests for a Better Future: Sustainability, \\ Innovation, Interdisciplinarity, 15-30 November 2020; Available online: https://iecf2020.sciforum.net.
}

Citation: Santacruz-García, A.C.; Nazareno, M.A.; Bravo, S. Could Fire Severity Promote the Biosynthesis of Bioactive Compounds as a Strategy to Enhance Plant Survival? Environ. Sci. Proc. 2021, 3, 19. https://doi.org/ 10.3390/IECF2020-08083

Academic Editors: Angela Lo Monaco, Cate Macinnis-Ng and Om P. Rajora

Published: 13 November 2020

Publisher's Note: MDPI stays neutral with regard to jurisdictional claims in published maps and institutional affiliations.

Copyright: (c) 2020 by the authors. Licensee MDPI, Basel, Switzerland. This article is an open access article distributed under the terms and conditions of the Creative Commons Attribution (CC BY) license (http://creativecommons.org/licenses /by/4.0/).

\begin{abstract}
Fire has effects on diverse aspects of plant functioning and development, many of them linked to survival. However, the response of native vegetation to this disturbance possibly reveals a plant strategy to tolerate fire linked to the biosynthesis of compounds such as chlorophylls and secondary metabolites. The aim of this study was to evaluate whether fire severity could promote biochemical tolerance to fire by influencing the biosynthesis of chemical compounds. To test this, six woody species from the Chaco region were exposed to an experimental burn of medium severity at the end of fire season in the study area. In this burn, individual plots for each plant were established. Fire severity was estimated visually as the burnt biomass of each plant, which was considered as the percentage of the loss of aboveground biomass. Then, the biochemical plant response to fire was studied, through the changes in the concentration of photosynthetic pigments (chlorophyll and carotenoids), and secondary metabolites (phenolic compounds and tannins). The metabolite quantification was carried out by using spectrophotometric methods. As a result, a strong correlation was found between the biosynthesis of metabolites in response to fire and the amount of burnt biomass during the experimental burns. This correlation could be considered as an indicator of the burnt plant response to stress. In our results, shrubby species showed both the higher amount of burnt biomass and the enhanced biosynthesis of compounds in the resprouts postfire, which could be related to the capacity of these species to be established in disturbed environments. Our study provides new insights into the understanding of the plant strategies to fire tolerance and resilience in natural environments.
\end{abstract}

Keywords: bioactive compounds; fire; fire severity; plant response to fire; plant survival

\section{Introduction}

The fire impact on vegetation depends mainly on three factors, the characteristics of the fire event, the plant storage reserves to regrowth post-disturbance, and the growth form of the species [1]. Fire tolerance is usually considered as the survival and regeneration capacity after fire. Accordingly, the plant response to the disturbance is closely related to the fire severity [2]. This severity includes the intensity and duration of the event and it indicates the degree to which vegetation has been affected by this disturbance. In particular, burnt biomass is considered as a measurement of fire severity [3].

Due to the loss of aerial biomass during the disturbance, plants activate the production of resproutings as a survival strategy to recover their vegetative structure [4]. This disturbance response is conditioned by the availability of biochemical reserves in 
bud banks and meristems. Therefore, the recovery of photosynthetic efficiency is closely related to the plant biochemical composition, as these compounds allow the production of resproutings and influence plant survival [4,5].

A high availability of plant reserves allows a high investment in defense and regeneration structures to guarantee their establishment post-disturbance [4]. Moreover, as the main defense mechanism, plants synthesize bioactive compounds whose function is to grant them protection against environmental changes generated by disturbances [6,7]. These compounds, such as the photosynthetic pigments (chlorophylls and carotenoids) and the secondary metabolites (as phenolic compounds and tannins), contribute to enhance the plant response against the biotic and abiotic stress caused by the environmental changes. Consequently, the link between burnt biomass during a fire event with the plant biochemical response could also be considered as an indicator of the burnt plant response to stress and, besides, it could also influence plant survival.

In this study, the fire severity effect on the biosynthesis of bioactive compounds as photosynthetic pigments and secondary metabolites was evaluated. A positive correlation between fire severity (measured as the burnt biomass) and the biosynthesis of bioactive compounds could be considered as an indirect bioindicator of the plant tolerance to fire.

\section{Methods}

\subsection{Study Area}

The Argentine Western Chaco Region is characterized by a seasonal semiarid climate and fire has been a frequent ecological event from the late 19th century [8]. Our study site was located in the National Agricultural Technology Institute's 'Francisco Cantos' Experimental Station in Santiago del Estero, Argentina ( $28^{\circ} 030 \mathrm{~S}, 64^{\circ} 150$ E). This experimental field has an area of approximately 8000 ha and includes the typical vegetation units of the Western Chaco Region: forests, savannas, grasslands and shrubs in different states of conservation. The selected woody species were: Schinopsis lorentzii (tree), Aspidosperma quebracho-blanco (tree), Sarcomphalus mistol (tree), Celtis ehrenbergiana (shrub), Atamisquea emarginata (shrub) and Schinus johnstonii (shrub), due to their representativeness in the study area.

\subsection{Experimental Burn and Biochemical Measurements}

An experimental burn was carried out in October 2016 during the flammability peak of the Chaco Region [9]. The experiment had a completely randomized design with individual plots $2 \mathrm{~m} \times 2 \mathrm{~m}$. Five replications per species were used. Each replication consisted of an individual plant ( $\mathrm{DBH}<15$, total height $<2 \mathrm{~m}$ ) located in the center of the plot. The experimental burn was of medium severity (fine fuel load $4000 \mathrm{~kg} \mathrm{DM} \mathrm{ha}^{-1}$ ). Burnt biomass was estimated visually by two operators.

For chlorophyll and carotenoid contents, samples of each burnt plant were collected six and twelve months after the burn. As control, samples of five unburnt plants were randomly collected in the same site and on the same dates. The determinations were performed according to the methodology proposed by Coria-Cayupán [10]. To evaluate the long-term effect of phenolic compounds and tannins in the plant response to fire, samples of each burnt plant were collected twenty-four months after the experimental burn. Similarly, as control, samples of five unburnt plants were randomly collected in the same site and date. The assessments of these compounds were performed according to García [11].

\subsection{Statistical Analysis}

A principal component analysis (PCA) was performed using the total contents of the post-fire biosynthesized metabolites studied in this work. The first axis of the PCA was considered as the biosynthesis of bioactive compounds value. The correlation between the burnt biomass and the bioactive compounds was performed through a Pearson's 
correlation coefficient. The statistical software used was Infostat/2017 (InfoStat Group, Universidad Nacional de Córdoba, Argentina) with an $\alpha=0.05$.

\section{Results and Discussion}

Results showed that the experimental burn caused a variation in the bioactive compounds evaluated within a short temporal scale (short-term effect). The first two axes of the PCA performed to evaluate the biosynthesis of bioactive compounds using the total contents of the post-fire biosynthesized metabolites explained $71 \%$ of the data. The Pearson's correlation coefficient between burnt biomass and the first component of the biosynthesis of bioactive compounds showed a significant association between them (Pearson's $p=0.40, p$-value $=0.0014$; Figure 1$)$.

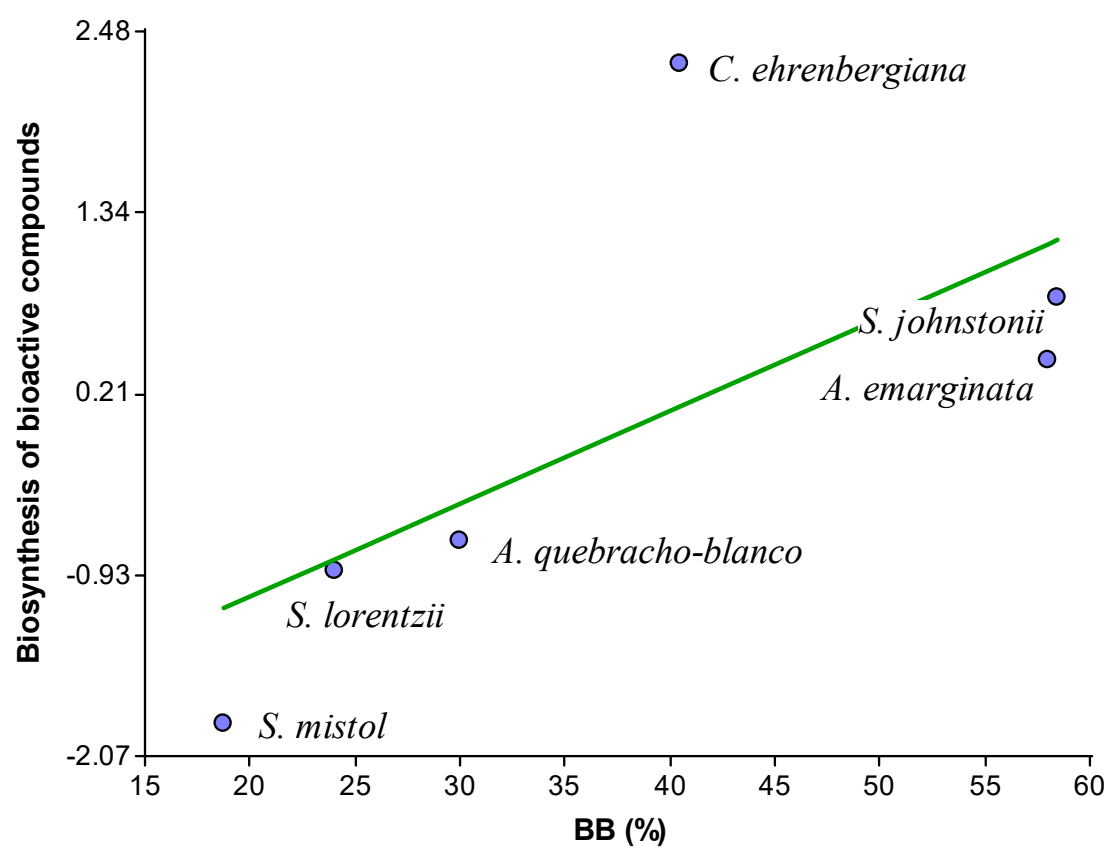

Figure 1. Correlation between the burnt biomass (BB) during the experimental burn and the first component of the biosynthesis of bioactive compounds. The green line shows where points would have a perfect correlation between the burnt biomass and the biosynthesis of compounds. Species below the line had a higher content of bioactive compounds in relation to the percentage of biomass consumed during the experimental burn, while species above the line had a greater loss of biomass during the burn compared to the content of bioactive compounds biosynthesized post-fire.

Results about burnt biomass suggested different fire severity among species studied, showing that shrubby species (C. ehrenbergiana, A. emarginata and S. johnstonii) were more seriously affected than tree species (S. mistol, S. lorentzii and A. quebracho-blanco). Additionally, the first-mentioned species showed the highest values of biosynthesis of compounds in response to fire. These results suggest that fire severity could affect the post-fire plant responses observed in our study.

Our results suggest that in low-intensity events (such as the experimental burn performed in this work), the correlation between the biosynthesis of bioactive compounds and the amount of burnt biomass during the experimental burn could be considered as an indicator of the burnt plant response to stress and, indirectly, as a bioindicator of the plant tolerance to fire. Thus, this study allows us to suggest that its association contributes to the post-disturbance vegetation establishment.

The highest values of the bioactive compound biosynthesis of shrubby species could be related to the investment in defensive structures to protect against physical or mechanical disturbances such as herbivory and fires, among others. These results could 
contribute to explain the capacity of these species to be established in disturbed environments [12], as the main function of these compounds is the plant protection against environmental stress [13]. The greater availability of plant reserves allows a greater investment in defense and regeneration structures to guarantee their establishment post-disturbance [4].

\section{Conclusions}

These findings confirm our hypothesis suggesting that fire severity could influence the biosynthesis of chemical compounds which could indirectly enhance plant survival. Our results showed that a fire event, such as the experimental burn carried out in this study, could produce variations in the biosynthesis of bioactive compounds, in response to the environmental stress caused by the disturbance. Accordingly, these compounds could be considered as indirect bioindicators of plant tolerance to fire, due to the strong correlation between the burnt biomass and the post-fire biosynthesized metabolites. The increase in the bioactive compound concentrations contributes to protect the burnt plants in the post-fire environmental conditions, as a main defense mechanism against oxidative stress conditions.

Author Contributions: Conceptualization, A.C.S.-G., M.A.N., and S.B.; Methodology, A.C.S.-G.; writing-original draft preparation, A.C.S.-G., S.B. and M.A.N.; writing-review and editing, S.B. and M.A.N.; All authors discussed the results and commented on the manuscript. All authors have read and agreed to the published version of the manuscript.

Funding: This research was funded by the Universidad Nacional de Santiago del Estero (UNSE); Consejo Nacional de Investigaciones Científicas y Técnicas (CONICET) and the Ministry of Science, Technology and Productive Innovation. Besides, A.C.S.-G. acknowledges for her fellowship granted by CONICET.

Conflicts of Interest: The authors declare no conflict of interest.

\section{References}

1. Bravo, S.; Gimenez, A.M.; Kunst, C.; Moglia, G. El fuego y las plantas. In Fuego en los Ecosistemas Argentinos; Instituto Nacional de Tecnología Agropecuaria: Santiago del Estero, Argentina, 2003; pp. 61-70.

2. Bran, D.; Cecchi, G.; Gaitán, J.J.; Ayesa, J.; Lopez, C. Efecto de la severidad de quemado sobre la regeneración de la vegetación en el Monte Austral. Ecol. Austral 2007, 17, 123-131.

3. Montorio, R.; Perez-Cabello, F.; García-Martin, A.; Vlassova, L.; De la Riva, J. La severidad del fuego: Revisión de conceptos, métodos y efectos ambientales. In Geoecología, Cambio Ambiental y Paisaje: Homenaje al Profesor José María García Ruiz; Instituto Pirenaico de Ecología, Universidad de La Rioja: Logroño, Spain, 2007; pp. 427-440.

4. Clarke, P.J.; Lawes, M.J.; Midgley, J.J.; Lamont, B.B.; Ojeda, F.; Burrows, G.E.; Enright, N.J.; Knox, K.J.E. Resprouting as a key functional trait: How buds, protection and resources drive persistence after fire. New Phytol. 2013, 197, 19-35, doi:10.1111/nph.12001.

5. Pérez-Harguindeguy, N.; Diaz, S.; Garnier, E.; Lavorel, S.; Poorter, H.; Jaureguiberry, P.; Bret-Harte, M.S.S.; Cornwell, W.K.K.; Craine, J.M.M.; Gurvich, D.E.E.; et al. New Handbook for standardized measurment of plant functional traits worldwide. Aust. J. Bot. 2013, 61, 167-234, doi:10.1071/BT12225.

6. Balasundram, N.; Sundram, K.; Samman, S. Phenolic compounds in plants and agri-industrial by-products: Antioxidant activity, occurrence, and potential uses. Food Chem. 2006, 99, 191-203, doi:10.1016/j.foodchem.2005.07.042.

7. Martins, S.; Mussatto, S.I.; Martínez-Avila, G.; Montañez-Saenz, J.; Aguilar, C.N.; Teixeira, J.A. Bioactive phenolic compounds: Production and extraction by solid-state fermentation. A review. Biotechnol. Adv. 2011, 29, 365-373, doi:10.1016/j.biotechadv.2011.01.008.

8. Torella, S.A.; Adámoli, J. Situación ambiental de la ecoregión del Chaco Seco. In Situación Ambiental Argentina 2005; Brown, A.D., Marinez Ortiz, U., Acerbi, M., Corchera, J., Eds.; Fundación Vida Silvestre, Argentina: Buenos Aires, Argentina, 2005 ; pp. 75-82.

9. Santacruz-García, A.C.; Bravo, S.; del Corro, F.; Ojeda, F. A comparative assessment of plant flammability through a functional approach: The case of woody species from Argentine Chaco region. Austral Ecol. 2019, 44, 1416-1429, doi:10.1111/aec.12815.

10. Coria-Cayupán, Y.S.; De Pinto, M.I.S.; Nazareno, M.A. Variations in bioactive substance contents and crop yields of lettuce (lactuca sativa L.) cultivated in soils with different fertilization treatments. J. Agric. Food Chem. 2009, 57, 10122-10129, doi:10.1021/jf903019d. 
11. García, E.M. Efecto de Metabolitos Secundarios Sobre la Fermentación Ruminal in vitro e in vivo. Obtención de Productos Cárnicos Resistentes a la Oxidación; Ph.D. Thesis, Universidad Nacional de Santiago del Estero, Santiago del Estero, Argentina, 2015; pp. $1-198$.

12. Conti, G.; Díaz, S. Plant functional diversity and carbon storage-An empirical test in semi-arid forest ecosystems. J. Ecol. 2013, 101, 18-28, doi:10.1111/1365-2745.12012.

13. Cannac, M.; Pasqualini, V.; Barboni, T.; Morandini, F.; Ferrat, L. Phenolic compounds of Pinus laricio needles: A bioindicator of the effects of prescribed burning in function of season. Sci. Total Environ. 2009, 407, 4542-4548, doi:10.1016/j.scitotenv.2009.04.035. 